\title{
Mercury Toxicity in Wildland Firefighters: A Progress Report
}

\section{Authors}

George Montopoli, William R. Smith, Hank Harlow, Mark Menolascino, A. J. Wheeler, and Andy Byerly 


\title{
MERCURY TOXICITY IN WILDLAND FIREFIGHTERS A Progress Report
}

\author{
$\longrightarrow>$ \\ GEORGE MONTOPOLI $\downarrow$ MATHEMATICS DEPARTMENT \\ WESTERN ARIZONA COLLEGE $\uparrow$ YUMA \\ WILLIAM R. SMITH $\uparrow$ ST. JOHN'S HOSPITAL $\downarrow$ JACKSON \\ HANK HARLOW $\downarrow$ DEPARTMENT OF ZOOLOGY AND PHYSIOLOGY \\ UNIVERSITY OF WYOMING $\uparrow$ LARAMIE \\ MARK MENOLASCINO $\downarrow$ ST. JOHN'S HOSPITAL $\downarrow$ JACKSON \\ A. J. WHEELER $\uparrow$ ST. JOHN'S HOSPITAL $\downarrow$ JACKSON \\ ANDY BYERLY $\downarrow$ ST. JOHN'S HOSPITAL \ JACKSON
}

\begin{abstract}
$\uparrow \quad$ AbStract
After the sudden emergence of mercury $(\mathrm{Hg})$ poisoning in bald eagles in the Greater Yellowstone Ecosystem in December 2005, we began a preliminary study to investigate if $\mathrm{Hg}$ accumulated at toxic levels in wildland firefighters who were exposed to smoke and other particulates while fighting fires in the western United States during summer 2007. Deviating from our original design, we were able to analyze blood from 12 subjects, and repeated blood draws occurred for only four of those subjects. Three of the subjects had measurable $\mathrm{Hg}$ levels that approached the limit of a nontoxic $\mathrm{Hg}$ concentration $(<10 \mathrm{mcg} / \mathrm{L})$. A fourth subject had a measurable level of $4 \mathrm{mcg} / \mathrm{L}$. All other subjects had levels designated by $<4$ $\mathrm{mcg} / \mathrm{L}$. For the four subjects with repeated blood draws, two demonstrated an increase in mercury levels over time $(<4$ to $7 \mathrm{mcg} / \mathrm{L}$, and 5 to $8 \mathrm{mcg} / \mathrm{L}$ ), one showed no change over time $(<4$ to $<4 \mathrm{mcg} / \mathrm{L})$, and one demonstrated a decrease in mercury levels over time ( 4 to $<4$ $\mathrm{mcg} / \mathrm{L}$ ). Beside $\mathrm{Hg}$, blood analyses were performed for the presence of four other metals:
\end{abstract}

lead, cadmium, cobalt, and thallium. Levels of these metals were well-below toxic thresholds and within normal range for all subjects. Although we recorded times of exposure to smoke for all subjects, our sample was too small to investigate any statistical inference about the relationship between the duration of exposure to smoke and changes in blood $\mathrm{Hg}$ concentration. As forest fires continue to ignite in the western U.S. at unprecedented levels, burning areas such as dried bogs and marshes, we highly recommend continued research and a mercurymonitoring program to ensure the continued health and safety of our firefighting crews.

\section{INTRODUCTION}

Since December 2005, approximately 15 bald eagles and one golden eagle (Aquila chrysaetos) were submitted for treatment to the Montana Raptor Conservation Center (MRCC). Analysis revealed that eagles contained toxic levels of $\mathrm{Hg}$ in their blood $(\geq 0.4 \mathrm{ppm}$ wet weight,. Six died, one was released, and the rest 
remain in treatment but most likely will not be releasable. Symptoms of $\mathrm{Hg}$ toxicity were expressed by at least three other eagles submitted prior to December 2005, but their blood was not analyzed specifically for this metal. We suspect that $\mathrm{Hg}$ poisoning may have emerged prior to December 2005, but was not diagnosed. The presence of $\mathrm{Hg}$ or other contaminants in bald eagles suggests environmental contamination that may eventually manifest itself in the human population.

Since summer 2006, blood samples from more than 100 nestling, migratory (fall and spring), and wintering eagles in Montana and Wyoming were collected in an attempt to monitor and locate the source of the mercury poisonings (Harmata 2006, Montopoli et al. 2008). They expected to locate origins of the contaminants, but none materialized. All eagles had detectable levels of contaminants in their blood, most notably $\mathrm{Hg}$. For example, during fall 2007, Harmata et al. trapped 22 wintering bald eagles in southwestern Montana, and results indicated that $\mathrm{Hg}$ loads in the bald eagles were very high (geometric mean $=10.0 \mathrm{mcg} / \mathrm{L}$; toxicity level $>4 \mathrm{mcg} / \mathrm{L}$ ); and, during summers 2006 and 2007, nestlings in northwestern WY (10 and 15, respectively) were sampled for contaminants and results suggested elevated levels of $\mathrm{Hg}$ that increased by $64 \%$ over the two summers.

Natural degassing of the earth's crust is the major source of environmental $\mathrm{Hg}$ worldwide (Heinz 1996) and coal-fired utilities are the largest single unregulated anthropogenic source of $\mathrm{Hg}$ emissions in the United States (USEPA 1997). However, recent data indicate wildfires are responsible for massive aerosols of $\mathrm{Hg}$ (Friedli et al. 2003, Wiedinmyer and Friedli 2007) and could release 15 times more $\mathrm{Hg}$ into the air than every U.S. coal-fired power plant combined (Friedli et al. 2001). Biswas et al. (2003) indicated combustion of litter and green vegetation resulted in virtually complete release of $\mathrm{Hg}$ stored in forests in the Rocky Mountain region. Montana and Wyoming forests may contain large reservoirs of $\mathrm{Hg}$ deposited during the industrial age that can now be released into the atmosphere during fires. Also, $\mathrm{Hg}$ concentrations in fish are influenced by the extent (size) of clear-cut forests in relation to area of lakes in the Canadian boreal forests (Garcia and Carignan 2005). These data suggest large scale logging operations contribute to $\mathrm{Hg}$ contamination and bioaccumulate in higher trophic level piscivorous predators (Driscoll et al. 1994).

Harmata (2006) speculated that "... Perhaps higher concentrations in Wyoming nestlings are a function of their proximity to Yellowstone National Park where large, extensive forest fires occur regularly and geothermal activity abounds...These fires release $\mathrm{Hg}$ into the atmosphere not only from trees consumed but especially peat that absorbed disproportionate amounts of atmospheric $\mathrm{Hg}$ emitted during the industrial age (Turetsky et al. 2006). Advancing global climate change and associated desiccation and emolation of temperate and boreal forests, exacerbated by extensive clear-cutting, may increase poisoning of aquatic ecosystems with high levels of $\mathrm{Hg}$ in the future."

In late May 2007, while discussing the issue of $\mathrm{Hg}$ poisoning in bald eagles, we theorized that, if forest fires are the source of $\mathrm{Hg}$ contamination in the bald eagles, the contaminant could also manifest itself in other species, most notably wildland firefighters who occupy the immediate environment while combating forest fires. Exposure of firefighters to $\mathrm{Hg}$ may occur: 1) after its release into the atmosphere as a result of combustion of mercury-laden tree bark and other organic plants; and, 2) while firefighters inhale particulates resulting from activities such as digging fire line in unburned areas, especially peat bogs where microorganisms methylized the inorganic mercurial ion under riparian conditions.

During summer 2007, we therefore initiated a preliminary study to investigate if $\mathrm{Hg}$ accumulated at toxic levels in wildland firefighters who were exposed to smoke and other particulates while fighting fires in the western United States.

\section{AnAlysis AND Results}

The null and alternative research hypotheses were defined by:

$\mathrm{H}_{0}$ : There are no statistically discernible differences in $\mathrm{Hg}$ levels in blood of firefighters after exposure to smoke-related contaminants.

$\mathrm{H}_{1}$ : There is a statistically discernible increase in $\mathrm{Hg}$ levels in blood of firefighters 
after exposure to smoke-related contaminants.

The original, proposed design involved the collection and analysis of $10 \mathrm{~mL}$ blood samples drawn from 26 subjects that were involved in fighting wildland fires during summer 2007. Full-time employees (seasonal or permanent) of Grand Teton National Park and Bridger Teton National Forest qualified as potential subjects in the study. We intended to take 2 draws per subject (pre- and postcontaminant exposure) and analyze the results using a related-samples t-test based on the repeated-measures design. A power analysis based on the difference score (post-Hg level minus pre-Hg level) allowed the detection of a medium effect due to $\mathrm{Hg}$ (Cohen's $\mathrm{d}=0.5$, alpha $=0.05$ and power $=0.8$; Cohen 1988). All tests were performed by a lab certified for the detection of Hg (St. John's Medical Center, P.O. Box 428 Jackson, WY 83001).

Participants were also asked to answer a brief questionnaire containing questions about demographics, prior mercury exposure, immediate exposure to smoke and particulates, and contact information.

Circumstances which we did not anticipate required us to substantially deviate from our original design. We were able to analyze blood from 12 subjects, and repeated blood draws occurred for only four of those subjects. Table 1 summarizes data obtained in our study.

Although our study specifically investigated $\mathrm{Hg}$, analyses were performed for four other metals (lead, cadmium, cobalt, and thallium). Levels of these metals were wellbelow toxic thresholds and within normal ranges for all subjects.

Eleven of the 12 subjects were males, and the average age of all subjects was 32.5 years. Prior to the first blood draw, each subject was exposed to smoke for 20.1 days, at 11.6 hours per day on average. Prior to the second blood draw, each subject was exposed to smoke for 21.9 days, at 10.8 hours per day on average.



Table 1. Blood Hg Level (mcg/L) of Firefighters and

Their Exposure to Smoke

? Indicates missing information

* Indicates no blood draw for the subject

\section{$\downarrow$ DISCUSSION}

This study was motivated by the sudden emergence of $\mathrm{Hg}$ poisoning in bald eagles in the Greater Yellowstone Ecosystem, specifically southwestern Montana in December 2005. Subsequent research of nestling, migratory and wintering bald eagles of southern Montana and northwestern Wyoming starting summer 2006 and continuing through the present further indicated abnormally high, and sometimes toxic, levels of $\mathrm{Hg}$ and other contaminants in these populations. Investigation into possible sources of contamination led us to the hypothesis that the high levels of $\mathrm{Hg}$ encountered in bald eagles originated from the extensive forest fires that the western United States is currently experiencing. These fires are releasing smoke and other particulates containing $\mathrm{Hg}$ at unprecedented levels from trees contaminated with $\mathrm{Hg}$ during our industrialization, and from peat bogs containing biota that absorbed $\mathrm{Hg}$ and have recently dried out due to our current warming climate trend.

During May 2007, we speculated that wildland firefighters in the western United States were being exposed to $\mathrm{Hg}$ as a result of the combustion of mercury-laden tree bark and peat bogs. Realizing the significance of $\mathrm{Hg}$ contamination to our firefighters and 
environment, we proposed to investigate if $\mathrm{Hg}$ accumulated at toxic levels in the blood of the firefighters.

Circumstances which we did not anticipate required us to substantially deviate from our original design. The Institutional Review Board (IRB) process, a required procedure when conducting human-oriented research, was substantially more involved than anticipated. After realizing the research topic in late May and assembling the research team in mid-June, we obtained substantial assistance from the University of Washington's Medical School in procuring IRB approval in late July. Consequently, we were not able to obtain blood samples for subjects prior to the start of the fire season, nor were we able to sample 26 subjects as originally proposed (the fire season had ended for many of the seasonal employees). We were, however, able to analyze blood from 12 subjects, and repeated blood draws occurred for four of those subjects.

Conclusions drawn from such a small sample are tenuous at best. However, the following results merit attention:

1) Beside $\mathrm{Hg}$, blood analyses were performed for the presence of four other metals (lead, cadmium, cobalt, and thallium). Levels of these metals, though not precisely reported $(<3.0 \mathrm{mcg} / \mathrm{dL},<0.5 \mathrm{mcg} / \mathrm{L},<1.0 \mathrm{mcg} / \mathrm{L}$, and $<1.0 \mathrm{mcg} / \mathrm{L}$, respectively, for all subjects), were well-below toxic thresholds and within normal range for all subjects.

2) Three of the subjects had measurable $\mathrm{Hg}$ levels $(7 \mathrm{mcg} / \mathrm{L}, 7 \mathrm{mcg} / \mathrm{L}$, and $8 \mathrm{mcg} / \mathrm{L})$ that approached the limit of a non-toxic $\mathrm{Hg}$ concentration $(<10 \mathrm{mcg} / \mathrm{L})$. A fourth subject had a measurable level of $4 \mathrm{mcg} / \mathrm{L}$. All other subjects had levels designated by $<4 \mathrm{mcg} / \mathrm{L}$.

3) For the four subjects with repeated blood draws, two demonstrated an increase in mercury levels over time $(<4$ to $7 \mathrm{mcg} / \mathrm{L}$, and 5 to $8 \mathrm{mcg} / \mathrm{L}$ ), one showed no change over time $(<4$ to $<4 \mathrm{mcg} / \mathrm{L})$, and one demonstrated a decrease in mercury levels over time ( 4 to $<4 \mathrm{mcg} / \mathrm{L}$ ).

4) Although we recorded times of exposure to smoke for all subjects, our sample was too small to investigate any statistical inference about the relationship between the duration of exposure to smoke and changes in blood $\mathrm{Hg}$ concentration.
We initiated this preliminary study to investigate if $\mathrm{Hg}$ was accumulating at toxic levels in wildland firefighters who were exposed to smoke and other particulates while fighting fires in the western United States. We experienced limitations to our original design because we sampled only 12 subjects who had lower exposure to smoke than anticipated. However, we still encountered $\mathrm{Hg}$ at measureable levels in four subjects, while no other metals were even precisely measureable in any of the subjects. Consequently, we feel this research merits further investigation with the following modifications:

1) The study should be expanded to a significantly larger sample of wildland firefighters in the western United States (at least 150 , contingent on funding). A majority of the firefighters should belong to hot-shot crews that are extensively exposed to fire contaminants (smoke and particulates) over the duration of the summer. Other firefighters with less exposure can be used as a comparative sample.

2) It is essential that $\mathrm{Hg}$ levels in each subject are analyzed a minimum of two times during the firefighting season, optimally: i) prior to commencement of the fire season; and ii) well into, or at the end of, the fire season after considerable exposure to fire particulates.

3) Time of exposure to smoke particulates by firefighters should be estimated more precisely.

4) $\mathrm{Hg}$ levels in subjects should be analyzed precisely, perhaps by an alternate method. Dr. Redeem Sumicab (pers. comm. 2007) has suggested a new procedure that analyzes urine from subjects drawn immediately upon awakening in the morning.

5) If the budget permits, hair samples from the back of the neck (which are fast growing) could be easily harvested to determine if mercury levels are due to chronic or acute exposure.

Analyses of data from ongoing bald eagle research indicate that elevated and toxic levels of $\mathrm{Hg}$ in nestling, migrating, and wintering eagles of southern Montana and northern Wyoming are persisting - even increasing - in the environment. Nestling bald eagles in Grand Teton National Park have experienced a $64 \%$ increase in mercury blood levels (Montopoli et al. 2008). As evidenced by the bald eagles in the 
rehabilitation center, once $\mathrm{Hg}$ toxicity fully manifests itself, there is poor prognosis for recovery. The same is true for humans.

Symptoms of elemental $\mathrm{Hg}$ toxicity in humans include central nervous system (CNS), renal, and pulmonary dysfunction: tremors; irritability; insomnia; memory loss; neuromuscular changes; headaches; slowed sensory, motor and cognitive function; mild transient proteinuria; acute renal failure; chest pains; dypsnea; cough; pulmonary function impairment; and interstitial pneumonia (ATSDR 1999, U.S. EPA 1997). Acute inhalation of methyl mercury results in severe CNS effects including blindness, deafness, and impaired level of consciousness (WHO 1990).

If research supports our hypotheses, we can implement immediate actions to prevent $\mathrm{Hg}$ toxicity and neurological compromise in wildland firefighters, such as: 1) the use of specialized equipment such as a wildland firefighter's mask; 2) periodic urine exams to monitor $\mathrm{Hg}$ concentration in body tissues; and/or, 3) if $\mathrm{Hg}$ concentrations become elevated, the use of DMSA (meso-2,3-dimercaptosuccinic acid) to remove the $\mathrm{Hg}$. As forest fires continue to ignite in the western U.S. at unprecedented levels, burning areas such as dried bogs and marshes, we highly recommend a mercurymonitoring program to ensure the continued health and safety of our firefighting crews.

\section{ACKNOWLEDGEMENTS}

We wish to extend our deepest appreciation to the following organizations and individuals for their collaboration in our research project: Dr. Alan Harmata, University of Washington Medical School (especially Geri Feris, HSR Administrator), Grand Teton National Park (especially Andy Fisher, Renny Jackson, Ed Visnovske, Chris Harder, Scott Guenther, Cindy O'Neill, and Lisa Elenz), Bridger Teton National Forest (Bridger Teton National Forest Helitack Crew, especially Chris Havener, Brad Koeckeritz, and Steve Markason; and BTNF Fire Management Overhead, especially Rod Dykehouse, Andy Norman, Kevin Pfister, and Chris Vero), University of Wyoming-National Park Service Research Station (Celeste Havener), and St. John's Medical Center (especially Redeem Sumicad).

\section{$\downarrow \quad$ Literature Cited}

Agency for Toxic Substances and Disease Registry (ATSDR) 1999. Toxicological Profile for Mercury. Public Health Service, U.S. Department of Health and Human Services, Atlanta GA.

Biswas, A., J. D.Blum and G. J. Keeler 2003. Forest fire effects on mercury and other trace metal concentrations in a Rocky Mountain forest ecosystem. EOS Transactions of American Geophysical Union 84 (46). Fall Meeting. Supplemental. Abstract \#B32C-05.

Cohen, J. 1988. Statistical power analysis for the behavioral sciences ( $2^{\text {nd }}$ ed.). New York: Academic Press.

Driscoll, C.T., C. Yan, C.L. Schofield, R. Munson, and J. Holsapple. 1994. The mercury cycle and fish in the Adirondack lakes. Environmental Science and Technology 28:136A$143 \mathrm{~A}$.

Garcia, E. and R. Carignan. 2005. Mercury concentrations in fish from forest harvesting and fire-impacted Canadian boreal lakes compared using stable isotopes of nitrogen. Environmental Toxicology and Chemistry 24:685-693.

Harmata, A., 2006. Monitoring Mercury And Other Contaminants In Bald Eagles In Southwestern Montana \& Northwestern Wyoming, Interim Report - 30 . November 2006.

Friedli, H.R., L. F. Radke, and J. Y. Lu. 2001. Mercury in Smoke from Biomass Fires. Geophysical Research Letters 28:32233226.

Heinz, G.H. 1996. Mercury poisoning in wildlife. Pgs. 118-127 In Noninfectious diseases of wildlife. A. Fair-brother, L.N. Locke, and G.N. Hoff (eds.). Iowa State University Press, Ames, Iowa, 
Montopoli, G., H. Harlow, A. Byerly, S. Wolff, S. Patla. 2008. Monitoring of heavy metal contaminants in nestling bald eagles of Grand Teton National Park. Submitted to Grand Teton National Park, April, 2008.

Radke, L.F., J.Y. Lu, C.M. Banic, W.R. Leaitch, J.I. MacPherson. 2003. Mercury emissions from burning of biomass from temperate North American forests: laboratory and airborne measurements. Atmospheric Environment 37:253-267

Sumicad, R. 2007. Personal comments. St. John's Medical Center, P.O. Box 428 Jackson, WY 83001.

Turetsky, M.R., J.W. Harden, H. Friedli, M. Flannigan, N. Payne, J. Crock, L. Radke. 2006. Wildfires threaten mercury stocks in northern soils. Geophysical Research Letters 33:10.
U.S. Environmental Protection Agency. 1997. Mercury Study Report to Congress, Volume V: Health Effects of Mercury and Mercury Compounds. Office of Air Quality Planning and Standards, Office of Research and Development.

Wiedinmyer, C and H. Friedli. 2007. Mercury emissions from fires: an initial inventory for the United States. Environmental Science Technology. 41, 8092-8093.

World Health Organization (WHO) 1990. Methyl Mercury. Volume 101. Distribution and Sales Service, International Programme on Chemical Safety, Geneva, Switzerland. 